\title{
A Study on the Images Used in Sandplay Therapy by Children Who Experienced the Gyeongju Earthquake*
}

\author{
Park, Chong Mee**
}

\begin{abstract}
$<$ Abstract $>$
The purpose of this study was to investigate the themes and images in the sandplay scenes of children who experienced the 2016 Gyeongju earthquake. The subjects of this study were children aged 3 to 6 years, and a total of four sessions of individual sandplay therapy was conducted once a week for 40 minutes per session. The children's stories were collected and their behaviors were categorized into themes and symbols commonly expressed. We identified a total of seven themes: attack, confusion, protection, precious things, mourning, emptiness, and energy to change. Individual sandplay therapy with the children was found to have a positive effect on their psychological recovery. We observed a decreasing tendency to use figures of soldiers, weapons, and religious spiritual images as they stabilized and their need for protection diminished, while images of construction, building facilities, and treasure increased over time.
\end{abstract}

Keywords : individual sandplay therapy, children who experienced earthquake, themes, images

* This paper is part of a 2018 master's thesis at Namseoul University

** Play therapist, Ribbon Center for Psychological Counseling (pcmangela@hanmail.net) 
Journal of Symbols \& Sandplay Therapy, Vol.9 No.2.

\section{I . Introduction}

Earthquakes are a deadly natural disaster that claims about 35,000 deaths annually across the globe. From 1990 to 2015, an average of 1,664 earthquakes with a magnitude of 5.0 or more occurred worldwide. On September 12, 2016, a powerful earthquake measuring 5.8 on the moment magnitude scale struck Gyeongju, North Gyeongsang Province in South Korea. This was the biggest earthquake ever to hit the Korean Peninsula, affecting not only its epicenter Gyeongju but also other cities in provinces of Gyeongsang like Daegu, Busan and Ulsan. Tremors were felt as far north as capital Seoul and far south as the island of Jeju. Gyeongju suffered approximately 500 aftershocks until the middle of October(Namuwiki, 2016).

A series of aftershocks usually follow a big earthquake, making it difficult to predict when and where the risk will occur. This may cause people experience difficulty with regards to perceived control over their surroundings(Ursano et al. 1994), make actual threat as well as subjective feeling of threat persist(Joo, Lee \&Ahn, 2017), and bring about physical problems and psychosomatic symptoms(Cao et al., 2003; Chen et al., 2001; Kukihara et al., 2014). Residents of disaster-stricken areas may experience acute stress reactions such as depression, agitation, nightmares, fear, dependence, and regression(Kim, 2006; Lee, 2005; Choi, 2006). If these reactions last more than a month, they can develop into a post-traumatic stress disorder (PTSD).

Because earthquakes are not a one-off event, it is necessary that affected regions conduct studies on children who are psychologically damaged by the disaster and/or provide support to the academic circles by accumulating data that can help draw up more effective support measures in the future.

Although no significant damage to human life or buildings were incurred by the 2016 Gyeongju earthquake, continued aftershocks heightened fear across the society and, from a micro-perspective, within families. Even young children are unaware of a disaster situation can show psychological responses, as parents' anxious response can pose a secondary threat. Contrary to adults, however, children face difficulty in becoming aware of or expressing symptoms of anxiety. Furthermore, because children are still undergoing the process of personality 
development, they are more susceptible to the negative effects of natural disasters and may react to them in a way that is quite different from that of an adult(Kim et al., 2014; Lacrox et al., 2007).

Unlike adults, children ideology, emotions, feelings, thoughts, and memories are in an undifferentiated state. And because their cognitive and language abilities have not yet developed fully, they are unable to describe their psychological experiences through verbal expressions but rather through non-verbal, symbolic expressions(Song \& Lee, 2002). Therefore, we might expect to see the use of particular symbols in case of young children who are underdeveloped both cognitively and verbally compared to children of other age groups, or children whose parents experience continued anxiety after the disaster. In other words, a different approach is needed to deal with anxiety in young children, and this effort requires the attention and appropriate intervention of the parents or close adults.

Professional help ought to be provided to children in disaster areas so as to facilitate their psychological stabilization. Although there is the study of Lee(2016) deals with the effect of sandplay therapy on adolescent victims of the April 2015 Nepal earthquake, no research has been done on psychological expressions that child victims make through sandplay therapy. Therefore, this qualitative research targeting children, who normally act on their instinct, aimed to see the following: the way children express their psychological state through sandplay, particular responses or symbolic expressions, psychological themes present through symbols, and differences in the use of figures in each session. The study also sought to collect basic data that could be conducive to helping these children.

The study of Lee(2016) found that group sandplay therapy has a positive effect on improving the psychological health and resilience of adolescent survivors of the Nepal earthquake. For example, there was a significant reduction in the shock level of parents who survived the earthquake. Also, among the sub-domains of parents' adult behavior problems, there was a significant improvement in the following items: anxiety depression, withdrawal, physical symptoms, attention problems, aggressive behavior, rule-breaking, internalizing problems, externalizing problems, adult behavior problems and somatic symptoms. There was also a significant improvement in all sub-domains of child behavior problems: anxiety, depression, 
Journal of Symbols \& Sandplay Therapy, Vol.9 No.2.

withdrawal, physical symptoms, social problems, thought problems, attention problems, aggressive behavior, rules-breaking, internalization and externalization. Common themes found in the sandpictures of adolescent survivors of the Nepal earthquake were daydreams, dangers, relationship between oneself and god, desires, relationships, boundaries and distinctions, marketplace, and creation. The study anticipated that sandplay therapy would have a similar positive effect on children who experienced the Gyeongju earthquake.

As children are more loial to their instinct than adolescents, this study sought to identify the different themes and symbols used in children's sandpictures.

The key research questions are as follows:

1. What themes are apparent in sandpictures created by children who experienced the Gyeongju earthquake?

2. What symbols are used in sandpictures created by children who experienced the Gyeongju earthquake?

\section{П. Research method}

\section{A. Participants}

This study provided individual sandplay therapy to 14 children(aged 3-6) who were at a daycare center in Gyeongju at the time of the earthquake. The therapist(researcher) and clients(participants) engaged in a total of four weekly sandplay sessions, from November 7 to December 2, 2016.

The study made phone calls or sent written letters or emails to daycare centers in Gyeongju in search for potential participants. Among the contacted centers, the study chose Center $\mathrm{K}$ as it showed a keen interest in the sandplay therapy program. An individual sandplay room was created inside the daycare building. The sandplay therapy administered in this study took a Kalffian approach, meaning that the participants engaged in a non-directive, non-structured play in a free and protected space. 
The program's structure(i.e., time and space), study objective, content and process were elaborately explained to the participants, their parents, and the teachers at the daycare center. All participants and their guardians agreed to have each session videotaped and sandpicture photographed. The characteristics of all 14 research participants are outlined in Table 1:

Table 1. Characteristics of participants

\begin{tabular}{cccccc}
\hline Participant & Age & Gender & Participant & Age & Gender \\
\hline A & 3 & M & H & 4 & M \\
\hline B & 3 & M & I & 5 & M \\
\hline C & 3 & M & J & 6 & M \\
\hline D & 3 & M & K & 6 & M \\
\hline E & 3 & M & L & 6 & M \\
\hline F & 3 & F & M & 6 & M \\
\hline G & 3 & F & N & 6 & F
\end{tabular}

\section{B. Research Procedure}

None of the participants could elaborate verbally their history and background, whom they were with at the time of the earthquake, what state they were in, and how they felt about the earthquake. The study therefore wanted to examine the effects that sandplay therapy has on these young children. Aside from taking videos and pictures, the researchers wrote down various verbal and nonverbal expressions as well as descriptions of the sandpictures in each session. The collected data was analyzed through the lens of Jungian interpretation of symbols. Moreover, themes and symbols commonly present in the sandpictures were grouped into different categories.

After the 2016 Gyeongju earthquake, sandplay therapy was given to 14 children aged 3 to 6 at a daycare center in Gyeongju between November 7 and December 2 in the form of individual therapy. The therapy took place in a therapeutic space created within the center. While the study intended to provide 4 weekly sessions to all participants, 3 of them took part in 3 sessions and 1 in 2 sessions. Thus the total number of therapy sessions was 51 . 
Journal of Symbols \& Sandplay Therapy, Vol.9 No.2.

\section{Method of Analysis}

After recording and collecting verbal comments and sandpictures in all sessions, symbols used by the participants were analyzed using the category of symbols created by Jang (2017a):

Table 2. Category of sandplay therapy symbols (23 items)

\begin{tabular}{|c|c|}
\hline Category & Type \\
\hline People & Farmer, police officer, firefighter, doctor, etc. \\
\hline Homeware & Furniture, household appliance, kitchen tool, etc. \\
\hline Structures & Building, bridge, tower, windmill, waterwheel, ruins, fence, etc. \\
\hline \multicolumn{2}{|l|}{ Food } \\
\hline Cars (vehicles) & $\begin{array}{l}\text { Road, sea and air transport, emergency vehicles like fire trucks, police vehicle, construction } \\
\text { vehicle, military vehicle, etc. }\end{array}$ \\
\hline \multicolumn{2}{|l|}{ Signs } \\
\hline \multicolumn{2}{|l|}{ Construction equipment } \\
\hline Soldiers & Modern soldier, ancient or Middle Age warriors or soldiers, armed soldier, etc. \\
\hline Weapons & Gun, cannon, tank, sword, spear, etc. \\
\hline Animals & Farm animal, ferocious animal, herbivore, imaginary animal \\
\hline Religious/spiritual figures & $\begin{array}{l}\text { Jesus, Buddha, Virgin Mary, Hindu gods, Islam gods, various god figures and } \\
\text { pagodas/stupas, religious items like candles, mountain spirit, wise old man, etc. }\end{array}$ \\
\hline $\begin{array}{l}\text { Imaginary and } \\
\text { archetypal beings }\end{array}$ & $\begin{array}{l}\text { - Imaginary animals: Unicorn, Pegasus, dragon, etc. } \\
\text { - Imaginary beings: Wizard, magician, fairy, witch, hero, villain } \\
\text { - People: King, queen, prince, princess, fairy, witch, wizard } \\
\text { - Shape: quaternity or quadrangle, mandala, cube, sphere, circle, square, triangle, pyramid, } \\
\text { sun, moon, star, etc. }\end{array}$ \\
\hline Treasures & Gold, jewel, bead, marble, crystal, precious stone, other precious items \\
\hline Trickster & Skull, gravestone, coffin, bone, monster, etc. \\
\hline Natural objects & Tree, wood, bush, flower, weed, fruit, plant, seashell, coral, etc. \\
\hline Natural structures & Mountain, rock, stone, waterfall, river, stream, pond, spring, well, volcano \\
\hline Construction materials & Tile, stick, clay, paper, string, glue, fishing line \\
\hline Fire & Candle, lighter, bonfire, campfire, other forms of fire \\
\hline Globes-shaped items & Ball, hot-air balloon, balloon \\
\hline \multicolumn{2}{|l|}{ Flag } \\
\hline Feminine items & Cinderella's glass slippers, mirror \\
\hline Addictive favorites & Alcohol, tobacco, tea \\
\hline Others & Snowman and other figures without a definite shape or purpose \\
\hline
\end{tabular}

Source: Jang (2017). Psychoanalytic Sandplay Therapy. Hakjisa. 


\section{Research results}

A total of 51 sandpictures were examined in this study: 12 pictures during session 1, 11 during session 2, and 14 during sessions 3 and 4 . Sandpictures and verbal comments that belong to each category were not included in this paper for space reasons.

Young children who experienced the Gyeongju earthquakes created a range of sandpictures according to their age and stage of development. Sometimes the figures would attack each other, often transform into new characters, and take on new roles. Sometimes the figures placed in the sand tray would later be taken out of the tray. A repeated play of burying, unearthing, killing, reviving, hiding, and seeking important symbolic elements was also observed. A single sandpicture would contain multiple themes. The same symbol would be used for different meanings. These observations were consistent with the study of Lee and Jang (2015), which confirmed that sandpictures do not necessarily show the stages of development in continuity, and that these stages repeatedly appear in various symbolic forms at different times.

\section{A. Themes in Sandpictures}

Based on videos, sandpictures and other materials collected from individual sandplay sessions, the study identified the themes present in sandpictures and categorized them into following seven groups: aggression, confusion, protection, emptiness, mourning, precious object, and energy of transformation.

\section{B. Symbols Used in Sandpictures}

The study first identified symbols most frequently used by the participants. Among 51 sandpictures, in a descending order, 45 sandpictures contained animals(88.23\%), 41 contained cars $(80.39 \%), \quad 30$ contained people(58.32\%), 24 contained structures(47.05\%), 22 contained treasures(43.13\%), 19 contained homeware(37.25\%), 18 contained soldiers and weapons (35.29\%), 17 contained imaginary/spiritual beings(33.33\%), 16 contained natural objects and natural structures(31.37\%), and 15 contained religions and spiritual figures(29.41\%). 
Journal of Symbols \& Sandplay Therapy, Vol.9 No.2.

Then the first sandpicture and the last sandpicture were compared to see if there were any changes in the use of the symbols. The use of animals, cars, people, imaginary/spiritual beings and natural objects remained similar. However, there was a decrease in the use of soldiers, weapons, natural structures and religious/spiritual figures, while there was an increase in the use of structures, treasures and construction equipment. Another fact worth noticing was that whereas construction equipment was not present in session 1 sandpictures, it appeared in 5 sandpictures created in the final session. In this study, "construction equipment" is defined as equipment used for the construction and maintenance of facilities such as airplane runway, taxiway and regular road. The study observed construction scenes where the ground was smoothed and hardened to make it safer and easier to travel. Although the participants mostly used their hands to make sand firmer and harder at the beginning, the movement became more dynamic in the last session as they used construction equipment to move sand and make it firmer, hence trying to create something.

Table 3. Difference in the use of symbols between the first and last sessions ( $N=$ number of sandpictures)

\begin{tabular}{cccccc}
\hline \multirow{2}{*}{ Category } & \multicolumn{2}{c}{ Figures used in the first session } & \multicolumn{2}{c}{ Figures used in the last session } \\
\cline { 2 - 5 } & $\mathrm{N}$ & $\%(/ 51$ & sandpictures $)$ & $\mathrm{N}$ & $\%(/ 51$ sandpictures $)$ \\
\hline People & 6 & 11.76 & 6 & 11.76 \\
\hline Homeware & 3 & 5.88 & 5 & 9.80 \\
\hline Structures & 3 & 5.88 & 6 & 11.76 \\
\hline Food & 1 & 1.96 & 2 & 3.92 \\
\hline Cars (Vehicle) & 9 & 17.64 & 10 & 19.60 \\
\hline Signs & 1 & 1.96 & 2 & 3.92 \\
\hline Construction equipment & 0 & 0 & 5 & 9.80 \\
\hline Soldiers & 6 & 11.76 & 2 & 3.92 \\
\hline Weapons & 6 & 11.76 & 2 & 3.92 \\
\hline Animals & 10 & 19.60 & 11 & 21.56 \\
\hline Religious/spiritual figures & 4 & 7.84 & 1 & 1.96 \\
\hline Imaginary/spiritual beings & 4 & 7.84 & 5 & 9.80 \\
\hline Treasures & 2 & 3.92 & 7 & 13.72 \\
\hline
\end{tabular}


Table 3. Difference in the use of symbols between the first and last sessions ( $N=$ number of sandpictures)

(continued)

\begin{tabular}{cccccc}
\hline \multirow{2}{*}{ Category } & \multicolumn{2}{c}{ Figures used in the first session } & \multicolumn{2}{c}{ Figures used in the last session } \\
\cline { 2 - 5 } & $\mathrm{N}$ & $\%(/ 51$ & sandpictures $)$ & $\mathrm{N}$ & $\%(/ 51$ sandpictures $)$ \\
\hline Trickster & 1 & 1.96 & 1 & 1.96 \\
\hline Natural objects & 3 & 5.88 & 4 & 7.84 \\
\hline Natural structures & 2 & 3.92 & 3 & 5.88 \\
\hline Construction materials & 0 & 0 & 1 & 1.96 \\
\hline Fire & 0 & 0 & 0 & 0 \\
\hline Globe-shaped items & 0 & 0 & 0 & 0 \\
\hline Flag & 0 & 0 & 0 & 0 \\
\hline Feminine items & 0 & 1.63 & 1 & 0 \\
\hline Addictive favorites & 0 & 0 & 0 & 0 \\
\hline Others & 0 & 0 & 0 & 0 \\
\hline
\end{tabular}

\section{Discussion}

The type of symbols used by participants in this research, in order of preference, are animals, cars, structures, treasures, homeware, soldiers and weapons, imaginary/spiritual beings, natural objects, natural structures, and religious/spiritual figures.

When observing the difference of used figures between the first and last sessions, there was not much difference in the use of animals, cars, people, imaginary/spiritual beings and natural objects. However, more figures in the categories of soldiers, weapons, natural structures and religious/spiritual figures were used in the first session than the last, whereas there was an increased use of figures in the categories of structures, treasures and construction equipment from the first session to the last. The change can be explained that, building on the instinctive energy of the unconscious, the experience of movement and transformation in the world of the conscious allowed ego to become stablished. The children were enthusiastic about sandplay and satisfied with their creations. Symbolisms related to the "protection" against their felt anxiety usually manifested in the form of angry figures. 
Journal of Symbols \& Sandplay Therapy, Vol.9 No.2.

Sandplay therapy allows children, for whom it is difficult to express thoughts and emotions in a verbal manner, to manifest their inner world, which seems to support the argument that sand moves and invites people to create. The door to the unconscious is open in the sand tray, and the participants and the researcher can enter the playground of the psyche through that door. In that playground, symbolic expressions and strong emotions arise, and the senses(touch, see, hear and smell) are awakened. It is said that children become aware of the touch sensation through their movement during play. As a matter of fact, the participants made the following comments as they touched sand: "It's soft like ice cream," "It feels like the powder that makes rice cakes," "It feels cool" and so on. Their eyes move together with their hands. The hands freely explored the sand through the act of digging, tapping, sweeping, stroking, marking, poking, patting, grabbing and scattering. During the sandplay process, children's bodies were bent forward in concentration. Sometimes their movements would be light(i.e., move around freely) but sometimes heavy(i.e., experienced difficulty in manifesting their problems). The process would sometimes be carried out at a fast pace, and sometimes at a slow pace. In sum, children's bodies took part in the play in a effective way.

Sometimes, we feel something new by seeing things on the earth; the moment we see intense lines or colors, or the sprouting of a new life, we get a sense of sacredness and develop faith. The earth has a transcendental meaning, with respect for human life(Lopez, 1989). For this reason, the earthquake is a powerful disaster that shakes the foundation of our lives. Through the archetypal motifs of the physical earth and the spiritual earth, the research embarked on the sandplay journey together with the children.

It appeared that the children were calling for the help of the earth goddess through the use of sand with their hands. The stories told and expressions made by the participants seemed to expand what the sandpicture provided, thus providing deep insights. Energies were manifested as the participants touched and used sand. In the last sandpictures, the work with the earth was done not through the hands but through more powerful construction equipment. These scenes that relate to the building of the path toward an inner journey, or toward healing, were highly significant. 
Some children grasped the figures firmly in their hands and then let go. Some observed their creation in the sand tray by circling around it, or looked at it from their eye level or from above, like a bird looking down from the sky. The children also spoke in the form of onomatopoeia, e.g., a child let out a sibilant humming sound with while playing with a vacuum cleaner. Some children pronounced certain words like a baby, e.g., saying "way" for whale and "puh-puh" for people and so on. Sometimes they took a sharp breath, sighed, whispered to the therapist, mumbled to themselves, or did not speak at all. Through these observations, the researcher was able to feel the emotions that are deeply rooted in the children's body movements.

The research considered the sandpictures as an expression of the participants' psychological pain, as well as the process of healing and development that will follow. They could also be interpreted as an expression of their psychic energy, as they reflect the inner symbolic process that leads to changes in both the inner and outer worlds. The stories told by the participants were also taken into account. Memories of the past, things that are recognized or experienced in the present, imaginations of the future, and the unconscious elements at a worldly level - all are images that connect the conscious and the unconscious, which allowed the research to confirm that the sacred play of sandplay therapy is an interesting therapeutic approach.

\section{A. Seven Themes Found in Sandpictures}

\section{1) Aggression}

There were sandpictures in which dinosaurs or monsters attack each other, which can be a symbol of aggression. The invasion of dinosaurs, snakes, beasts, and monsters in the sandplay process is the work of the children's brain, at an unconscious level, to consciously and intentionally control the stimulus, or the earthquake, which stirs up anxiety that is difficult to handle and explain. Emotions surrounding natural disasters like earthquakes, abuse, domestic violence, severe stress and anger are usually symbolized by aggression displayed by dinosaurs, snakes, wild beasts and the like(s) in the sandpictures of not only children but also adolescents and adults(Jang, 2017b). 
Journal of Symbols \& Sandplay Therapy, Vol.9 No.2.

As animals of the past, dinosaurs can represent a child's past or history. Children reproduce events of the past in their play. Dinosaurs are powerful-looking animals that provoke fear. They are predators. Dinosaurs are now extinct, which means they also represent death. Children who are afraid of death may display their fear through a play involving a toy dinosaur. Children who experienced the death of someone significant tend to choose dinosaurs more often than other toys, a behavior that may indicate their fear of losing not only an important person in their lives but also their inner peace(Jang et al., 2009).

In the presence of threat, the psyche tends to bring balance through the presence of animals, symbols of instinct, in dreams or symbol work. Jung gave the example of dreams with snakes. The snake is the representative of the world of instinct, especially of those vital processed which are psychologically the least accessible of all. Snake dreams sometimes indicate a discrepancy between the attitude of the conscious mind and instinct, the snake being a personification of the threatening aspect of that conflict. This is because we have an archetypal disposition to recognize the danger of something long and serpentine that slithers, with sharp fangs and flickering tongue split into two"(Jung , 1984/2007).

Snakes are more than just scary animals to man. We associate them with something highly unpleasant. People universally dislike snakes, though there may be differences in its degree. Snakes arouse feelings of shock, fascination, fear and horror. We see snakes as unpredictable, fast, vigilant and ready to attack.

Snakes have various meanings and characteristics. Aborigines believed that snakes produce the energy of all life forces. Snakes have two opposing aspects: creative and destructive. In ancient religions, snakes were often used to symbolize the head of gods. With their mysterious and has invisibility in it, it can be said that it is primordial formlessness. Having qualities of mystery and invisibility, we could say that a snake is a primordial formlessness. The appearance of a snake heralds the beginning of various elements becoming mixed; it implies the potential dance with a newly-created energy. Through the power of the snake, we are reminded of an instinctive life.

\section{2) Chaos}

The theme of chaos was represented by various figures - animals, houses, cars, 
furniture, etc. - either lying on the sand or knocked down by the participants.

Psychological damages from natural disasters can be exacerbated depending on individual's existing trauma(Rhi, 2012). Whether these children had trauma prior to the earthquake is unknown, but they explained that the figures mentioned above are "lying down."

Confusion or chaos can appear in a sandpicture when cutoff and disorder at a severe level are manifested(Turner, 2009). If the child is around the age of three, however, a chaos picture can be part of the normal development. Chaos can be regarded as a state of intangibility that precedes creation, in which it holds the ability to regenerate.

Earthquakes and other forms of natural disasters provoke existing wounding/trauma of an individual, which leads to psychological and/or physical health issues. Psychological and physical health problems arise from external stresses and internal readiness conditions resulting from natural disasters(Rhi, 2012). But the concept of inner preparedness is not applicable to the research as the participants are young children. Internal readiness conditions refer to the weakening of ego-consciousness triggered by personal traumas, lack of continuity of ego-consciousness, and dangerous emotional complexes within the unconscious threatening the conscious.

There are opinions that it is healthier to express the earthquake experience as a "small story" of difficulties in ordinary life, rather than a "big story" of a natural disaster, in the sand tray. This idea is suggested by scenes in which various objects have been knocked over. Chaos breaks down boundaries and brings about the state of disintegration, but also opens up the possibility to re-enter a state of integration. With the disintegration of normal boundaries, chaos breaks out of the daily time and space and occurs within a sacred time. Chaos occurs cyclically within superstitious emotions related to the belief that the past vanishes whenever it enters chaos. The process of chaos is a new beginning that regenerates time(Eliade, 1958). Recreating the earthquake or other dangerous situation in the sand tray is equivalent to re-experiencing the psychological trauma and thus can be seen as a sign of recovery.

\section{3) Protection}

Amid the chaos, the theme of protection is present through the use of god, soldier, 
Journal of Symbols \& Sandplay Therapy, Vol.9 No.2.

fence, tree and pagoda figures. When a natural disaster strikes, people often turn to archetypal images of their religion or gods. Recollecting god images at times of crisis is the attempt to maintain a psychological balance by the psyche. In particular, it is a constellation of the Self archetype in the collective unconscious(Jung, 1984/2007). Thus, when the constellated archetypal energy of the unconscious is the outcome of a natural disaster, they are experienced as god. Human beings need images of god to prevent ego function from being inundated by the archetypal energy. Jung noted that there are countless magical rites with the sole aim of protecting individuals from the unexpected and dangerous inundation by the unconscious(Jung, 1984/2007). In the region of Andong in South Korea, rituals such as giving offerings and performing a mask dance were conducted whenever there were signs of unfortunate events, like plague, as people believed those signs indicated the descent of gods.

Such rituals can be attributed to the perception that it is the gods who give life and abundance to mankind, and at the same time bring natural disasters like the earthquake. Minimizing the damages incurred by the nature of these gods, which is irresistible, is the reinforcement of the ego-consciousness. However, existing traumas or individual complexes that stem from those traumas can interfere with effort to minimize the archetypal damage to the ego.

From a humanistic viewpoint, the relationship between archetypes and gods is akin to the relationship between man and the many native religions across the world. But when we look at the relationship between God who created the cosmos and man - in other words, from a biblical point of view - it could be a completely different story. Just as unstable mother-child attachment can cause an individual to become unstable for a lifetime, human beings may not develop the concept of god in their lives if the qualities of gods are not inherent in their personality. In this regard, those who had forgotten gods created many rituals so as to not incur the wrath of these gods that exist in their imagination.

Those who abandoned the creation gods may have created their own gods or performed various rituals because of their primitive relationship with those gods, which is inherent in human nature. Perhaps the human nature, which is true to basic instinct, needed the image of god to prevent the unconscious archetypal energy, which is experienced as god 
according to Jung, from overwhelming the ego function. These behaviors were a type of initiation(Lee, 2012). At the same time, however, man glorifies nature, which brings about great disasters, or the gods they created. In contrast, the relationship between God and man described in the Bible is entirely different. The Bible says that God sends rain(i.e., blessings) on the righteous and the unrighteous(Matthew 5:45). To those who did not follow the truth but led a rich life, Matthew 6:2, 5 and 16 say, "They have received their reward in full." In other words, eternal happiness and comfort are not promised to them. Instead, they will experience a second death.(Revelations, 20:14). The Bible also depicts God as the wellspring of life, and that He does not want the death of evil man(Ezekiel 18:31, 33:11).

Kawai(2015), who administered sandplay therapy to those affected by tsunami, noted that we humans had dual emotions of fascination and fear toward nature. When a natural disaster occurs, humans are afraid of the power of nature behind it. Indeed, the Japanese are said to have built hundreds of Shinto shrines on the seashore. At the same time, humans are attracted by the power of nature that provides abundant resources for them and they construct temples to acknowledge this. This is a natural behavior, considering the human nature.

Somatic symptoms, one of the typical symptoms of trauma, might not appear as having a direct relationship. But when the ego's ability to endure the impact of earthquakes is weak, it is the body that absorbs and expresses the impact in lieu of the ego. Therefore, the absence of expressions of earthquakes in psychotherapeutic settings such as sandplay therapy does not necessarily rule out any direct association with earthquakes. In other words, one should not assume that earthquake victims dealing with relationships or environments unrelated to earthquakes in their sandpictures are not expressing earthquakes.

\section{4) Emptiness}

Young children aged around three moved the figures in and out of the sand tray. Their hands, which mostly felt the texture of sand at the beginning, became more dynamic as therapy progressed.

Trauma not only remains in our memory but also is remembered physically, emotionally and sensually(Linda \& Daniel, 2007). Experiences that remain in the senses in 
Journal of Symbols \& Sandplay Therapy, Vol.9 No.2.

particular can hardly be described by language, and can be felt as powerful emotions(Van der Kolk, 1996). Sandplay therapy can help individuals to revitalize their senses through nonverbal and visual experiences, hence allowing them to directly express their experiences. Turner(2009) said that many children express their interest in figures but hardly place them in the sand tray during the initial phase of sandplay therapy, and the research could observe such a phenomenon even during the short process.

The research was not able to confirm whether the children saw frogs jumping out from the shaking ground during the earthquake, but there was a feeling that frog figures were used as a symbol of emptiness preceding hope. Frog as a symbol of transformation is attributable to the extraordinary degree of its shape-shifting: from round egg to tadpole to long-limbed amphibian. In fairytales, frogs transformed into princes or princesses. The fact that the frog is one of the first animals to show up in spring also added to the animal's symbol of transformation. After the freezing winter when all seem dead, the frog heralds the beginning of a new season, in which all forms of life blossom, by crawling out of the ground. Is it too paradoxical to say that the frog was used as a symbol of hope, as a reaction to emptiness?

\section{5) Mourning}

The participants often sprinkled sand gently over the figures in the sand tray, murmuring statements like, "It's raining from heaven," "Water" and "This is cloud." The gentle and almost holy movement of the hands seemed to have a ritual significance. From an archetypal level, sprinkling or scattering is a cycle of the beginning and the end. The act of scattering stimulates a deep inner connection, bringing about the ability to interact and respond to the outside world and also to begin relationships. Realizing the connection between oneself and the nature can lead to a profound psychic transformation, although children may not be conscious of it(Turner, 2009).

Scattering, pouring and dropping sand as well as burying figures in sand can often be seen in sandplay therapy. Scattering sand can be linked to the mythical behavior for fertile land. Scattering sand is like "scattering seeds." The custom of sprinkling or scattering is a primitive pattern in the unconscious of human beings, who are repeatedly born again in the 
cycle of seasons. Moreover, the participants left marks of their hands on the sand, which can be an indication of the emergence of a new life. Eliade, through research on religion and anthropology, specifically mentioned that agricultural rituals across many cultures are related to making field more fertile. Regardless of region or culture, people engaged in a ritual of spreading water or ashes upon soil to make it fertile. In this regard, the act of scattering is sacrificial; it is an act of worship by returning what was given to us back to earth. The act of scattering or sprinkling shows that awareness, at a deep level, that we are inevitable connected to all things that exist(Eliade, 1958).

\section{6) Precious object}

Some children put coins or marbles inside a box and buried it in the sand. Treasure represents a sublimated form of the symbolism of the color gold, a solar attribute, as opposed to gold as coins, which signifies exaltation of and corruption by earthly desires. The treasure is usually found in a cave, and in this case the cave has double meanings: One is the mother, and the other is the unconscious containing "the elusive treasure." Jung maintains that the treasure which the hero wins only after painful effort is nothing less than himself reborn in the cave in which introversion or regression has confined him. The hero, in so far as he remains bound to the mother-principle, is himself the dragon, but in so far as he remains bound to the mother-principle, is himself the dragon, but in so far as he is reborn of the mother, he is the conqueror of the dragon, and therefore of his former self(Bradway, 1997). Dora Kalff referred to this as "the Self," and Vries(1984) to the task of seeking the hidden treasure in alchemy.

The box can be used to represent a secret that others do not know of, and to hide that secret. It can also be used to set boundaries, and to contain the child's emotions. It can also symbolize the child's inner conflict. Children engage in an imaginary play of giving a gift to someone using boxes. They also use boxes as a symbol of themselves. For instance, they would put valuables inside a box and say, "There's something valuable in here that other people don't know of." Considering the box or the object contained within the sandplay process could allow us to know what their meanings are for the child. Although it might not 
Journal of Symbols \& Sandplay Therapy, Vol.9 No.2.

be meaningful if the child does not reveal what the object inside symbolizes, the act of not opening the box could itself could symbolize trust. Using a box in the first session might indicate that the child wants to communicate something in a secretive manner. As such, expressing something in an indirect manner suggests that perhaps the child does not yet trust the therapist. At the same time, it gives the child a control over the situation. The child is the only one who knows the secret inside the box, and can disclose that secret in the way that he or she chooses. In this regard, the child restores his or her ability to control a situation. Hence, the child is able to express his or her problems at the right speed, through the right method(Jang, 2017a).

Burying and excavating something could be an indication of the child's discovering his or her inner treasure. Often, young children bury something in the sand and ask the therapist to find it. Even in this research, a five-year-old boy hid a treasure inside the sand during the last session and asked the therapist to find it before leaving the room.

The act of burying something can have various meanings. It could be that the child is trying to hide something precious, protect his or her vulnerabilities. It could indicate the potential of the growth of something, just like seeds buried in the ground. There is also the possibility that the child is trying to conceal something scary or unbearable. Things that lie dormant in the shadows of the unconscious can be compromise the ego. In addition, burying could be associated with experienced difficulties, being trapped or figuratively "buried" somewhere, or the state of helplessness.

Burying could imply the attempt to control something that has not yet been dealt with, or the attempt to have something out of sight. Burying is a ritual involving something that an individual is afraid to see or become aware of, and it is done, at least partially, consciously. Repeated touching and scattering of the sand as well as burying something inside could represent a movement toward disintegration.

Among figures that the participants identified as a "treasure," crystal figures were often used. The crystal is that treasure gained with difficulty: a Self symbol. In alchemy, that crystal is the philosopher's stone. Alchemists claimed that the stone is comprised of the body, spirit and psyche, and is the living essence. A philosopher's stone or a crystal is a symbol of 
the inner world or the whole man of noble spirit(Jung, 1977). A crystal is also a symbol of wholeness(Bradway, 1997). It also has the meaning of wisdom, intuitive knowledge, psyche, intelligence and eyes. Crystals are a tool through which magicians see the future; they show the possibility of the birth of the conscious. Here, there is transference by the therapist to the magician. Crystals allow individuals to connect with one's inner wisdom. The healing power of the crystal is manifested at various levels, and allows individuals to expand their capability so as to embrace the luminosity. The crystal, through which the light penetrates, also seemed to represent the wishes of the participants.

\section{7) Transformative energy}

Sandpictures under this theme displayed active, dynamic movements with vitality. Construction vehicles and equipment were mobilized for construction, which can be seen as an attempt to break away from the disorder of the unconscious brought about by the earthquake and move toward a conscious ego. Many of the building that collapsed due to the earthquake were either old or made of bricks. Through the experience having their houses destroyed, the children perhaps also expressed their wish to have a sturdier house. It might also demonstrate the need for healing.

\section{V . Conclusion}

This study administered sandplay therapy to children who experienced the Gyeongjuearthquake to observe earthquake-related images in their sandpictures. Based on the children's verbal and nonverbal expressions as well as symbols and images in their sandpictures, the study identified common symbolisms and themes and grouped them into different categories.

Sandplay therapy offers an opportunity for children to express their inner contents through emotions in relation to the interaction between past and present experiences. It provides a space in which children can enhance their resilience through creative play and symbolic expression. 
Journal of Symbols \& Sandplay Therapy, Vol.9 No.2.

This study sought to identify the psychological state of children who experience an earthquake by grouping sandplay images and themes into different categories. Children have limits in delivering their experiences verbally. Sandplay therapy allows them to overcome this limitation. Through symbolic and metaphorical expressions of the traumatic experience, sandplay allows children to re-experience their trauma and achieve healing. This study was meaningful as it provided a direct therapeutic intervention to children who are assumedly experiencing direct and/or indirect stress from an earthquake at an important stage of development. Hopefully, the findings of this study will be useful to other studies of sandplay therapy of a similar nature.

Limitations of this study and suggestions for future related studies are as follows:

First, the program lasted for a short period of time. Future studies ought to be conducted for a longer duration so as to confirm whether the effect of the program still remains significant even after a certain period of time.

Second, children's individual attribute could not be taken into consideration at a deep level as no parent interview was held prior to the research. Therefore, it would be necessary for later studies to conduct a parent interview to obtain important information such as the state that the children were in during the earthquake, whom they were with, etc. It is recommended that future studies adopt a pretest-posttest design in which detailed preliminary investigation is conducted on the participants and post-assessment is made to confirm the therapeutic effect of sandplay therapy, which would help expand the connection between academic theories and actual clinical setting.

Third, because studies on the therapeutic intervention of sandplay therapy were never conducted for children who experience an earthquake, the study could not make a clear distinction between the anxiety children felt from the earthquake itself and the anxiety that stemmed from the anxiety displayed by their parents. Emotional development during young childhood is highly important. Earthquakes are a continuing disaster with, possibly, continuing damages. Thus related studies ought to be conducted on a continuous basis, through which we need to explore ways to educate the parent or make suggestions to professionals who deal with these children. 


\section{References}

Kim, K-T. (2006). Intervention theory of crisis: Danger of everyday life and method of handling(3rd ed.): Daewang-sa.

Kim, H-B., Sur, W-S., Gong, J-S., Bae, D-S. (2014). Korean assessment scale for post traumatic stress disorder for clinical practioner: A practical guide book for children and adolescents, Maxmedica.

Song, Y-H., Lee, E-J. (2000). Research for expression of child: Study of play therapy, 4(2), 29-44.

Lee, B-Y. (2012). Analytic psychology of Korean shamanism: Searching for agony and healing. Hangil-sa.

Lee, B-Y., Jang, M-K. (2015). Comparisons between North Korean adolescent defectors and south Korean adolescents in expressions in sandplay therapy. Symbols and sandplay therapy, 6(2), 31-45.

Lee, S-H. (2016). The effect of group sandplay therapy on psychological health and resilience of young survivors of Nepal earthquake. master's thesis at Namseoul university.

Lee, Y-J. (2005). Psychologic management of disaster crisis. Korean collection of theses for crisis management, 1(1), pp. 85-99.

Jang, M-K., Kim, Y-J., Yoon, H-K. (2009). Play therapy. Seoul: Changji-sa.

Jang, M-K. (2017a). Analytic psychological sandplay therapy. Hakji-sa.

Jang, M-K. (2017b). Archetypal symbolism in the recovery process from natural disaster: Sandplay therapy of earthquake adolescent survivors. Symbols and sandplay therapy, 8(2), 1-21.

Joo, H-S., Lee, N-B., Ahn, H-E. (2017). Mediating effects of trauma-related dysfunctional appraisals and self-stigma in the relationships of trauma severity and posttraumatic stress symptoms. Cognitive behavior therapy in Korea, 17(3), 341-364.

Choi, N-H. (2006). Post disaster support for victims: Rehabilitation of disaster victims. Korean collection of theses for crisis management, 2(2), 3-17

De Vries, A. (1984). Dictionary of symbols and imagery.

Bradway, K., \& McCoard, B. (1997). Sandplay-Silent workshop of the psyche. London/New York: Routledg.

Cao, H., McFarlane, A., \& Klimidis, S. (2003). Prevalence of psychological support, and the 
Journal of Symbols \& Sandplay Therapy, Vol.9 No.2.

tsunami. International review of psychiatry, 18, 213-216.

Chen, C. C., Yeh, T. L., Yang, Y. K., Chen, S. J., Lee, I. H., Fu, L. S. \& Chen, L. Y. (2001). Psychiatric morbidity and post-traumatic symptoms among survivors in the early stage following the 1999 earthquake in Taiwan. Psychiatry research, 105(1), 13-22.

Eliade, M. (1958). Pattern in comparative religions. Lincoln: Sheed and Ward.

Jung, C. G. (1984). Menschenbild and Gottesbild. Grundwerk C. G. Jung Bd. 4. Walter-Verlag AG. (Trans. into Korean in 2007 by Jung Institute of Korea)

Jung, C. G. (1977). Psycbology and alcbemy. (R. F. C. Hull, Trans.) Princeton: Princeton University Press. (Original work published 1953)

Kukihara, H., Yamawaki, N., Uchiyama, K., Arai S., \& Horikawa, E. (2014). Trauma, depression, and resilience of earthquake/tsunami/nuclear disaster survivors of Hirono, Fukushima, Japan. Psychiatry and clinical neurosciences, 68, 7.

Lacroix, L., Rousseau, C., Gauthier, M. F., Singh, A., Giguere, N., \& Lemzoudi, Y. (2007). Immigrant and refugee preschoolers sandplay representations of the tsunami. The arts in psychotherapy, 34, 99-113.

Linda, E. H. \& Daniel, S. S. Techniques of Sandbox: Practical guide book. (translated by Myung-sook Hwang. 2007 Seoul: Hakji-sa).

Lopez-Pedraza, R. (1989). Hermes and his children. Switzerland: Daimon.

Rhi, B-Y. (2012). Korean shamanism and analytical psychology: Searching for sufferings and healing. Seoul: Hangil-sa.

Turner, B. A. (2009). The handbook of sandplay therapy. Seoul: Hakji-sa.

Ursano, R. J., McCaughey, B. G., \& Fullerton, C. S. (1994). Individual and community responses to trauma and disaster: The structure of human chaos. Cambridge University Press.

van der Kolk, B. A., McFarlane, A. C., \& van der Hart, O. A. (1996). General approach to treatment of posttraumatic stress disorder. In B. A van der Kolk, A. C. McFarlane, L. Weisaet (Eds.), Traumatic stress the effects of overwhelming experience on mind, body, and society. New York. Guilford Press.

National Security Agency. "guide book for earthquake." http://www.mpss.go.kr

Received : October 25, 2018

Revised : December 15, 2018

Accepted : December 27, 2018 